\title{
Statistically significant but clinically unimportant: a systematic review and meta-analysis of the analgesic benefits of erector spinae plane block following breast cancer surgery
}

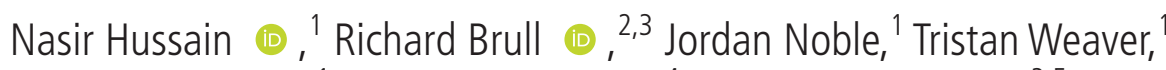 \\ Michael Essandoh, ${ }^{1}$ Colin JL McCartney, ${ }^{4}$ Faraj W Abdallah (10 ${ }^{3,5}$
}

- Additional material is published online only. To view, please visit the journal online (http://dx.doi.org/10.1136/ rapm-2020-101917).

${ }^{1}$ Anesthesiology, Ohio State University Wexner Medical Center, Columbus, Ohio, USA 'Women's College Research Institute, University of Toronto, Toronto, Ontario, Canada ${ }^{3}$ Anesthesiology and Pain Medicine, University of Toronto, Toronto, Ontario, Canada ${ }^{4}$ Department of Anesthesiology and Pain Medicine, University of Ottawa, Ottawa, Ontario, Canada

${ }^{5}$ Anesthesiology and Pain Medicine, University of Ottawa, Ottawa, Ontario, Canada

Correspondence to Dr Faraj W Abdallah, Department of Anesthesiology and Pain Medicine, University of Toronto, Toronto, Ontario, Canada; mank_abda@yahoo.ca

Received 14 July 2020 Revised 11 August 2020 Accepted 21 August 2020 Published Online First 9 November 2020

\section{Linked}

- http://dx.doi.org/10.1136/ rapm-2020-102152

Check for updates

(C) American Society of Regional Anesthesia \& Pain Medicine 2021. No commercial re-use. See rights and permissions. Published by BMJ.

To cite: Hussain $\mathrm{N}$,

Brull R, Noble J, et al.

Reg Anesth Pain Med

2021:46:3-12.

\section{ABSTRACT}

The novel erector spinae plane block (ESPB) has been reported to provide important postoperative analgesic benefits following a variety of truncal and abdominal surgical procedures. However, evidence of its analgesic efficacy following breast cancer surgery, compared with parenteral analgesia, is unclear. This meta-analysis evaluates the analgesic benefits of adding ESPB to parenteral analgesia following breast cancer surgery. Databases were searched for breast tumor resection trials comparing ESPB to parenteral analgesia. The two co-primary outcomes examined were 24-hour postoperative oral morphine equivalent consumption and area-under-curve of rest pain scores. We considered reductions equivalent to $3.3 \mathrm{~cm}$.h and $30 \mathrm{mg}$ oral morphine in the first 24 hours postoperatively for the two co-primary outcomes, respectively, to be clinically important. We also assessed opioid-related side effects and long-term outcomes, including health-related quality of life, persistent postsurgical pain and opioid dependence. Results were pooled using random effects modeling.

Twelve trials (699 patients) were analyzed. Moderate quality evidence suggested that ESPB decreased 24-hour morphine consumption and area-under-curve of rest pain by a mean difference $(95 \% \mathrm{Cl})$ of $-17.60 \mathrm{mg}(-24.27$ to $-10.93)$ and $-2.74 \mathrm{~cm} . \mathrm{h}(-3.09$ to -2.39$)$, respectively; but these differences were not clinically important. Highquality evidence suggested that ESPB decreased opioidrelated side effects compared with parenteral analgesia by an OR ( $95 \% \mathrm{Cl})$ of 0.43 (0.28 to 0.66$)$. None of the studies evaluated long-term block benefits.

Adding ESPB to parenteral analgesia provides statistically significant but clinically unimportant short-term benefits following breast cancer surgery. Current evidence does not support routine use of ESPB. Given the very modest short-term benefits and risk of complications, the block should be considered on a case-by-case basis.

\section{BACKGROUND}

Characterized by its technical simplicity and wide dermatomal spread (T1 to L3), ${ }^{12}$ the novel ultrasound-guided erector spinae myofascial plane block (ESPB) has gained popularity among practitioners for its benefits across a variety of truncal and abdominal surgical procedures. ${ }^{3}$ Applied to breast cancer surgery, the ESPB is purported to enhance pain control. ${ }^{4}$ However, much of the reviews evaluating ESPB in breast surgery are qualitative in nature ${ }^{5}$ and limited by pooling breast surgery together with thoracic procedures; ${ }^{6}$ while the most recent investigation conducted multiple comparisons to other truncal blocks and provided statistical conclusions devoid of clinical interpretations. ${ }^{7}$ As for individual randomized clinical trials, the results have been decidedly mixed ${ }^{8-10}$ and difficult to interpret, primarily because they involved comparisons to various other blocks. ${ }^{8} 1112$ In order to definitively address the analgesic efficacy of ESPB for breast cancer surgery, we aimed to compare the analgesic effects of ESPB to parenteral analgesia alone. The most valid, accurate and least biased evaluation of the treatment effect of an intervention is derived from comparisons with a placebo or no intervention. ${ }^{13}$

This systematic review and meta-analysis aims to identify the potential clinical role of ESPB in the setting of breast cancer surgery. We aimed to quantify the benefits of adding ESPB to parenteral analgesia compared with parenteral analgesia alone. Postoperative pain severity and analgesic consumption during the first 24 hours were designated as co-primary outcomes. We also assessed the effects of ESPB on patient satisfaction, health-related quality of life, risk of persistent postsurgical pain and long-term opioid dependence.

\section{METHODS}

In preparing this manuscript, we adhered to the Preferred Reporting Items for Systematic Reviews and Meta-Analyses (PRISMA). ${ }^{14}$ We sought randomized controlled trials (RCTs) that analyzed the analgesic effects of ESPB compared with parenteral analgesia in patients undergoing breast cancer surgery. These studies were evaluated using a predesigned protocol that was registered with the international prospective register of systematic reviews (PROSPERO) under the number CRD42020170496.

\section{Eligibility criteria}

We searched electronic databases for unilateral breast cancer surgery trials where adult patients were randomized to ESPB as an intervention compared with parenteral analgesia. Studies that had a co-intervention other than ESPB (eg, another 


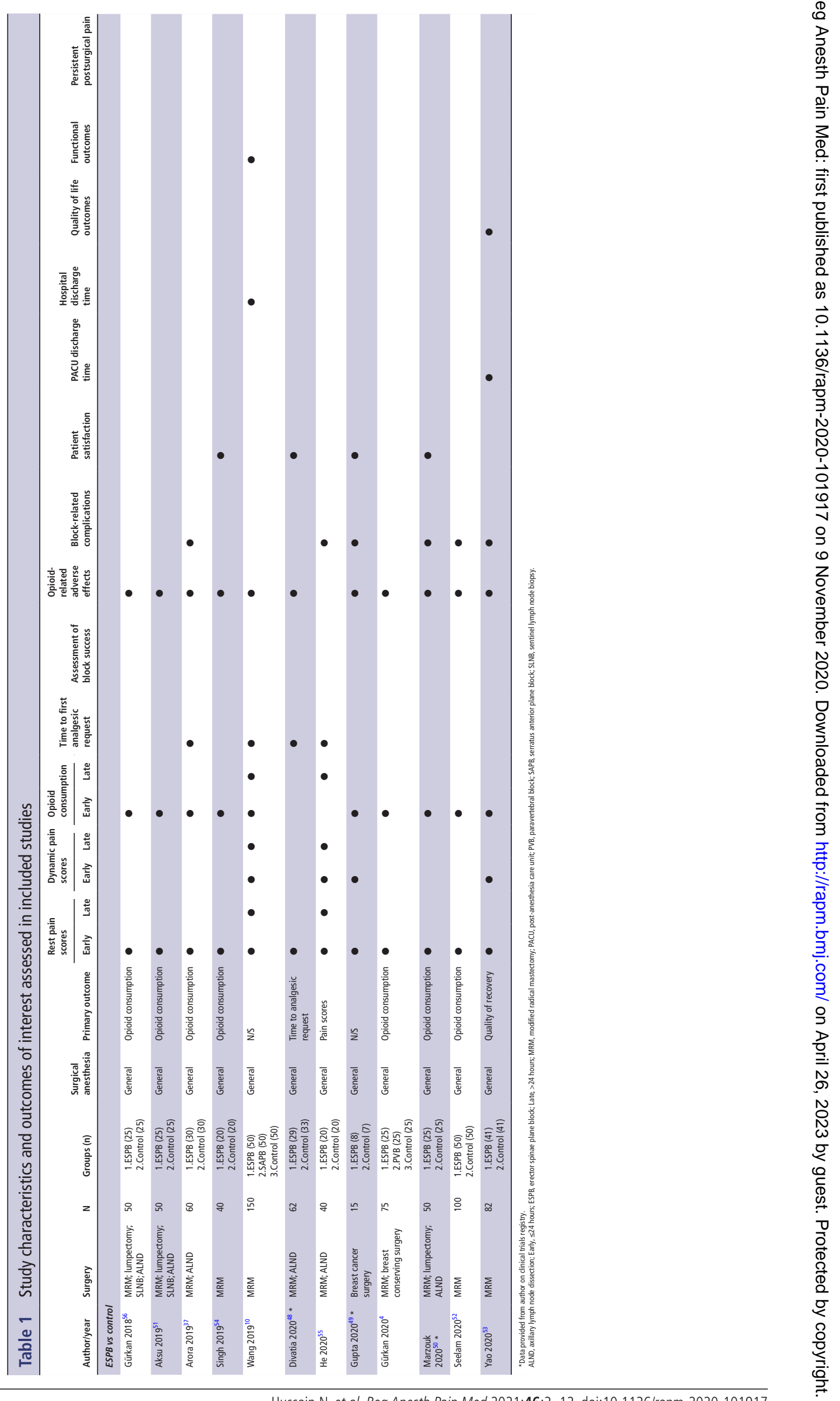


Table 2 Local anesthetic techniques for ESPB and analgesic regiments of included studies

ESPB

\begin{tabular}{|c|c|c|c|c|c|c|c|c|c|}
\hline Author/year & $\begin{array}{l}\text { Pre-incisional } \\
\text { analgesia }\end{array}$ & Surgical analgesia & $\begin{array}{l}\text { Supplemental } \\
\text { postoperative } \\
\text { analgesia }\end{array}$ & $\begin{array}{l}\text { Block } \\
\text { timing }\end{array}$ & $\begin{array}{l}\text { Block technique } \\
\text { 1. Unilateral } \\
\text { 2. Bilateral } \\
\text { 3. LA between } \\
\text { rhomboideus major } \\
\text { and erector spinae } \\
\text { 4. LA below erector } \\
\text { spinae and above } \\
\text { transverse process }\end{array}$ & $\begin{array}{l}\text { Level of } \\
\text { block }\end{array}$ & Localization & $\begin{array}{l}\text { Assessment of } \\
\text { block success }\end{array}$ & ESPB bolus \\
\hline Gürkan $2018^{56}$ & None & Fentanyl 2 mcg/kg IV & $\begin{array}{l}\text { Paracetamol } 1 \\
\text { g IV; tramadol } \\
100 \text { mg IV; PCA } \\
\text { morphine }\end{array}$ & Preop & 1,4 & $\mathrm{~T} 4$ & USG & No & $\begin{array}{l}20 \mathrm{~mL} 0.25 \% \\
\text { bupivacaine }\end{array}$ \\
\hline Aksu $2019^{51}$ & None & Fentanyl 2 mcg/kg IV & $\begin{array}{l}\text { Paracetamol } 1 \\
\text { g IV; tramadol } \\
100 \mathrm{mg} \text { IV; PCA } \\
\text { morphine }\end{array}$ & Preop & 1,4 & $\begin{array}{l}\mathrm{T} 2 \text { and } \\
\mathrm{T} 4\end{array}$ & USG & No & $\begin{array}{l}20 \mathrm{~mL} 0.25 \% \\
\text { bupivacaine }\end{array}$ \\
\hline Arora $2019^{37}$ & $\mathrm{~N} / \mathrm{S}$ & $\begin{array}{l}\text { Fentanyl } 0.5 \mathrm{mcg} / \mathrm{kg}-1 \\
\mathrm{mcg} / \mathrm{kg} \text { IV }\end{array}$ & PCA morphine & Preop & 1,4 & T5 & USG & Yes & $\begin{array}{l}0.4 \mathrm{~mL} / \mathrm{kg} 0.5 \% \\
\text { ropivacaine }\end{array}$ \\
\hline Singh $2019^{54}$ & None & Morphine $0.1 \mathrm{mg} / \mathrm{kg}$ IV & $\begin{array}{l}\text { Diclofenac } 1.5 \\
\mathrm{mg} / \mathrm{kg} \text { IV q8h; } \\
\text { morphine } 3 \mathrm{mg} \\
\text { IV prn }\end{array}$ & Preop & 1,4 & T5 & USG & Yes & $\begin{array}{l}20 \mathrm{~mL} 0.5 \% \\
\text { bupivacaine }\end{array}$ \\
\hline Wang $2019^{10}$ & $1 \mathrm{mcg} / \mathrm{kg}$ Dexmed & $\begin{array}{l}\text { Sufentanil } 0.4 \mathrm{mcg} / \mathrm{kg} \text { IV; } \\
\text { remifentanil } 3.5 \mathrm{ng} / \mathrm{mL} \text { to } \\
4.5 \mathrm{ng} / \mathrm{mL} \text { IV }\end{array}$ & $\begin{array}{l}\text { Flurbiprofen } \\
50 \text { mg PO prn; } \\
\text { sufentanil } 5 \\
\text { mcg IV prn; PCA } \\
\text { sufentanil }\end{array}$ & Preop & 1,4 & $\begin{array}{l}\text { T4 and } \\
\text { T5 }\end{array}$ & USG & $\mathrm{N} / \mathrm{S}$ & $\begin{array}{l}20 \mathrm{~mL} 0.375 \% \\
\text { ropivacaine }\end{array}$ \\
\hline Divatia $2020^{48}$ * & $\mathrm{N} / \mathrm{S}$ & Fentanyl 0.5 mg/kg IV & $\begin{array}{l}\text { Paracetamol } 15 \\
\mathrm{mg} / \mathrm{kg} \text { IV q8h; } \\
\text { fentanyl IV prn }\end{array}$ & Intraop & 1,4 & T5 & USG & Yes & $\begin{array}{l}20 \mathrm{~mL} 0.25 \% \\
\text { bupivacaine }\end{array}$ \\
\hline Gupta $2020^{49}$ * & $\begin{array}{l}0.5 \mathrm{mcg} / \mathrm{kg} / \mathrm{hr} \\
\text { Dexmed }\end{array}$ & $\begin{array}{l}\text { Fentanyl } 2 \mathrm{mcg} / \mathrm{kg} \text { (if no } \\
\text { block); ketamine } 10 \mathrm{mg} \\
\text { bolus (if block) }\end{array}$ & PCA morphine & Preop & 1,4 & T5 & USG & $\mathrm{N} / \mathrm{S}$ & $\begin{array}{l}30 \mathrm{~mL} 0.5 \% \\
\text { ropivacaine }\end{array}$ \\
\hline Gürkan $2020^{4}$ & None & $\begin{array}{l}\text { Fentanyl } 2 \mathrm{mcg} / \mathrm{kg} \mathrm{IV} \text {; } \\
\text { tramadol } 100 \mathrm{mg} \mathrm{IV;} \\
\text { paracetamol } 1 \mathrm{~g} \mathrm{IV}\end{array}$ & $\begin{array}{l}\text { Paracetamol } 1 \\
\text { g IV q6h; PCA } \\
\text { morphine }\end{array}$ & Preop & 1,4 & $\mathrm{~T} 4$ & USG & No & $\begin{array}{l}20 \mathrm{~mL} 0.25 \% \\
\text { bupivacaine }\end{array}$ \\
\hline He $2020^{55}$ & $\mathrm{~N} / \mathrm{S}$ & $\mathrm{N} / \mathrm{S}$ & $\begin{array}{l}\text { Flurbiprofen } 50 \\
\text { mg IV prn }\end{array}$ & Preop & 1,4 & T3 & USG & $\mathrm{N} / \mathrm{S}$ & $\begin{array}{l}20 \mathrm{~mL} 0.5 \% \\
\text { ropivacaine }\end{array}$ \\
\hline Marzouk $2020^{50}$ * & $\mathrm{N} / \mathrm{S}$ & $\mathrm{N} / \mathrm{S}$ & PCA morphine & Preop & 1,4 & T4 or T5 & USG & $\mathrm{N} / \mathrm{S}$ & $\begin{array}{l}40 \mathrm{~mL} 0.375 \% \\
\text { ropivacaine }\end{array}$ \\
\hline Seelam $2020^{52}$ & None & $\begin{array}{l}\text { Fentanyl } 0.5 \mathrm{mcg} / \mathrm{kg} \text { to } 1 \\
\mathrm{mcg} / \mathrm{kg} \mathrm{IV} \text {; paracetamol } \\
1 \mathrm{~g} \mathrm{IV}\end{array}$ & $\begin{array}{l}\text { Paracetamol } 1 \mathrm{~g} \\
\text { IV q8h; morphine } \\
2 \mathrm{mg} \text { to } 3 \mathrm{mg} \\
\text { IV prn }\end{array}$ & Preop & 1,4 & T4 & USG & No & $\begin{array}{l}30 \mathrm{~mL} 0.25 \% \\
\text { bupivacaine }\end{array}$ \\
\hline Yao $2020^{53}$ & $\begin{array}{l}\text { Flurbiprofen } 50 \\
\text { mg IV }\end{array}$ & $\begin{array}{l}\text { Sufentanil } 0.5 \mathrm{mcg} / \mathrm{kg} \mathrm{IV;} \\
\text { flurbiprofen } 50 \mathrm{mg} \text { IV q8h }\end{array}$ & $\begin{array}{l}\text { Flurbiprofen } \\
50 \text { mg q8h; } \\
\text { sufentanil } 2 \\
\text { mcg IV prn PCA } \\
\text { sufentanil }\end{array}$ & Preop & 1,4 & $\mathrm{~T} 4$ & USG & No & $\begin{array}{l}25 \mathrm{~mL} 0.25 \% \\
\text { ropivacaine }\end{array}$ \\
\hline
\end{tabular}

*Study from clinical trials registry.

Dexmed, dexmedetomidine; ESPB, erector spinae plane block; h, hour; Intraop, intraoperative; IV, intravenous; LA, local anesthesia; mcg, microgram; min, minute; mL, milliliter; ng, nanogram; N/S, not specified; PCA, patient-controlled analgesia; Preop, preoperative; prn, as needed; q, every; USG, ultrasound guidance.

block), which precluded identifying the analgesic effects of ESPB alone, were not considered. Studies of catheter-based continuous blocks were not considered. All types of breast tumor resection with or without concomitant axillary interventions were eligible, including mastectomy or partial mastectomy with or without axillary lymph node dissection or sentinel lymph node biopsy.

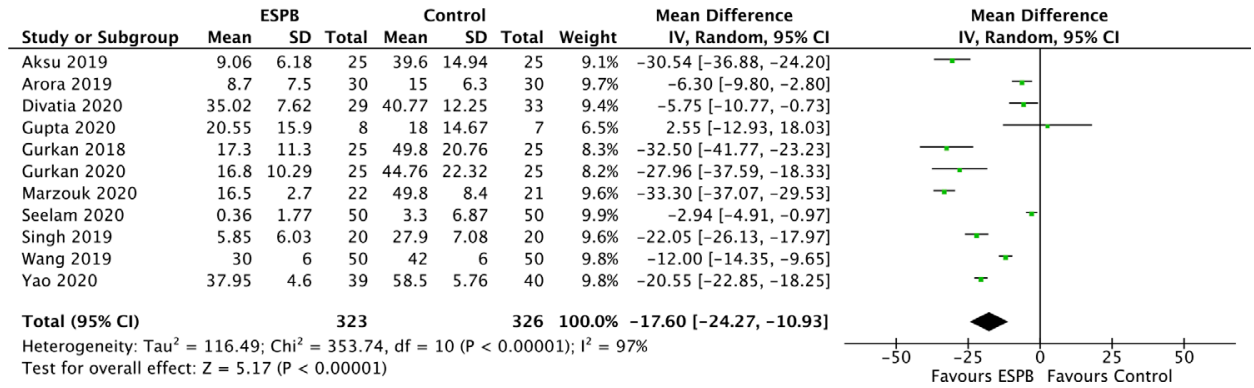

Figure 1 Forest plot of cumulative oral morphine equivalent consumption at 24 hours for erector spinae plane block (ESPB) versus parenteral analgesia (Control). Pooled estimates of the weighted mean difference are shown with $95 \% \mathrm{Cls}$. Pooled estimates are represented as diamonds and lines represent the $95 \% \mathrm{Cls}$. IV, intravenous. 


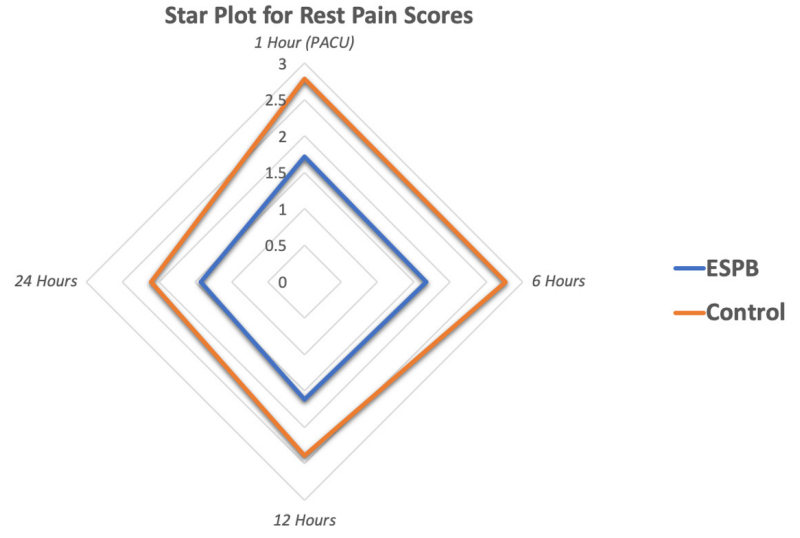

Figure 2 Graphical representation of the area under the curve of the pooled weighted mean pain scores at rest as measured by the visual analog scale $(0$ to $10 \mathrm{~cm}$ ) over time for erector spinae plane block (ESPB) versus parenteral analgesia (Control). PACU, post-anesthesiacare unit.

Cosmetic procedures (eg, augmentation, reduction mammoplasty or isolated breast reconstruction) or use of tumescence were exclusion criteria. Also, trials of volunteers or those not reporting analgesic outcomes were excluded. No language restrictions were placed; and non-English studies were translated using an online translator.

\section{Search methods}

A systematic search strategy was created by an evidence-based medicine librarian (LB) for the US National Library of Medicine database, MEDLINE; the MEDLINE In-process and Other Non-Indexed citations database; the Excerpta Medica database, Embase; and the Cochrane Database of Systematic Reviews from October 2016 (date of original ESPB description) to May 1, 2020. The strategy contained key words relating to the following: breast surgery, erector spinae plane, pain control, and analgesia. The complete search strategy for the MEDLINE database can be viewed in online supplemental appendix A. The reference lists for all articles satisfying inclusion criteria were reviewed to identify any potentially relevant trials. We also reviewed clinical trial registries (www.clinicaltrials.gov (US Clinical Trials Registry);

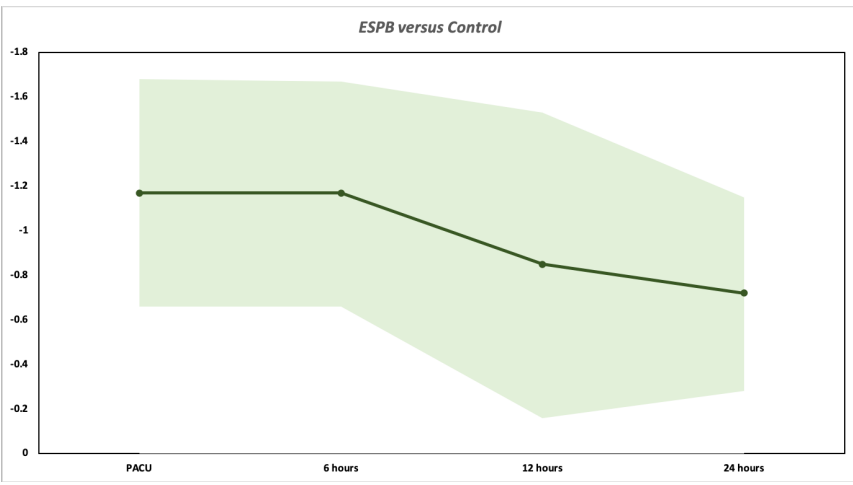

Figure 3 Line graph for weighted mean difference (WMD) in rest pain severity scores across 24-hours at four time points (post-anesthesia care unit (PACU), 1 hour, 6 hours, 12 hours, and 24 hours) between erector spinae plane block (ESPB) versus parenteral analgesia (Control). Pooled estimates of the WMD for each time point are represented by the dark line and $95 \% \mathrm{Cls}$ are represented by surrounding shaded region. Values less than zero represent a rest pain benefit. https://apps.who.int (International Clinical Trials Registry Platform; www.ctri.nic.in (Indian Clinical Trials Registry); https:// www.irct.ir (Iranian Clinical Trials Registry); http://www.chictr. org.cn (Chinese Clinical Trials Registry); and http://www.clinicaltrials.in.th (Thai Clinical Trials Registry)) for potentially eligible ongoing or completed trials. Finally, we reviewed the proceedings of international conferences (American Society of Anesthesiologists (ASA) 2011 to 2020, American Society of Regional Anesthesia and Pain Medicine (ASRA) 2013 to 2020, the European Society of Regional Anesthesia (ESRA) 2014 to 2019, American Association of Cancer Research (AACR) 2014 to 2020, and the European Society of Anesthesiology (ESA) 2015 to 2020) for potentially eligible abstracts.

\section{Selection of included studies}

Two independent reviewers ( $\mathrm{NH}$ and JN) screened the search results based on title and abstract alone first; then potentially eligible citations had their full-text versions reviewed. Disagreements were resolved by discussion; if consensus could not be reached, a third reviewer (FA) made the final decision.

\section{Data extraction}

Two independent reviewers (NH and TW) carried out data extraction in duplicate. Disagreements were resolved by discussion; if consensus could not be reached, a third reviewer (FA) made the final decision. Extracted data included: year of publication; number of patients; type of surgery performed; intervention and comparator groups; ESPB technique; assessment of block success; means and measures of variance for interval postoperative pain scores and interval postoperative analgesic consumption; additional analgesic outcomes (time to analgesic request, level of patient satisfaction with pain relief; post-anesthesia care unit and hospital discharge times (hours); long-term outcomes (health-related quality of life, persistent postsurgical pain and opioid dependence); safety outcomes (block-related complications as local anesthetic systematic toxicity, bleeding and/or hematoma formation, pneumothorax, or nerve injury); and opioid-related side effects as respiratory depression, excessive sedation, pruritus, constipation, urinary retention). Graphically reported data not reported in textual form were extracted using a graph digitizing software (GraphClick, Arizona Software, USA).

\section{Assessment of methodological quality of individual trials}

Using the Cochrane Collaboration tool, ${ }^{15}$ the methodological quality of each of the included trials was assessed for risk of bias in six predefined domains including: random sequence generation, allocation concealment, level of blinding of study participants and personnel, blinding of outcome assessment, incomplete outcome data, and selective outcome reporting. ${ }^{15}$ For all risks of bias pertaining to patient and assessor blinding, we a priori decided to assign a high risk of detection bias to studies that lacked a sham ESPB. Two independent reviewers ( $\mathrm{NH}$ and FA) rated each included study as having either a low, unclear, or high risk of bias for each domain.

\section{Methodological quality across trials}

The overall methodological quality across statistically pooled outcomes was assessed using the Grades of Recommendation, Assessment, Development, and Evaluation (GRADE) guidelines. ${ }^{16} 17$ GRADE uses five categories-risk of bias, imprecision, inconsistency, indirectness and publication bias to address key issues that influence the quality of evidence which for each outcome is then classified as high, moderate, low, or very low. ${ }^{1617}$ 
Table 3 Secondary endpoint results

\begin{tabular}{|c|c|c|c|c|c|c|c|c|}
\hline Outcome & $\begin{array}{l}\text { Studies } \\
\text { included }\end{array}$ & $\begin{array}{l}\text { ESPB, mean (SD) } \\
\text { or } n / N\end{array}$ & $\begin{array}{l}\text { Control, mean } \\
\text { (SD) or } n / N\end{array}$ & $\begin{array}{l}\text { Mean difference or OR } \\
(95 \% \mathrm{Cl})\end{array}$ & $\begin{array}{l}\text { P value for } \\
\text { statistical } \\
\text { significance }\end{array}$ & $\begin{array}{l}P \text { value for } \\
\text { heterogeneity }\end{array}$ & $\begin{array}{l}\mathrm{I}^{2} \text { Test for } \\
\text { heterogeneity }\end{array}$ & $\begin{array}{l}\text { Quality of } \\
\text { evidence } \\
\text { (GRADE) }\end{array}$ \\
\hline $\begin{array}{l}\text { Rest pain at } 1 \text { hour (PACU) } \\
(\mathrm{cm})\end{array}$ & 11 & $1.72(1.61)$ & $2.78(1.75)$ & $-1.17(-1.68$ to -0.66$)$ & $\begin{array}{l}<0.00001 \\
\left(P_{c}=0.005\right)\end{array}$ & $<0.00001$ & $83 \%$ & $\oplus \oplus \oplus \ominus$ \\
\hline Rest pain at 6 hours $(\mathrm{cm})$ & 11 & $1.67(1.47)$ & $2.76(2.11)$ & $-1.17(-1.67$ to -0.66$)$ & $\begin{array}{l}<0.00001 \\
\left(P_{c}=0.006\right)\end{array}$ & $<0.00001$ & $82 \%$ & $\oplus \oplus \oplus \ominus$ \\
\hline Rest pain at 12 hours $(\mathrm{cm})$ & 9 & $1.62(1.61)$ & $2.39(2.00)$ & $-0.85(-1.53$ to -0.16$)$ & $0.02\left(P_{c}=0.010\right)$ & $<0.00001$ & $89 \%$ & $\oplus \oplus \oplus \ominus$ \\
\hline Rest pain at 24 hours $(\mathrm{cm})$ & 11 & $1.42(1.43)$ & $2.11(1.75)$ & $-0.72(-1.15$ to -0.28$)$ & $0.001\left(P_{c}=0.006\right)$ & $<0.00001$ & $88 \%$ & $\oplus \oplus \oplus \ominus$ \\
\hline $\begin{array}{l}\text { Rest pain at } 36 \text { hours } \\
(\mathrm{cm})^{*}\end{array}$ & N/A & $\mathrm{N} / \mathrm{A}$ & $\mathrm{N} / \mathrm{A}$ & $\mathrm{N} / \mathrm{A}$ & $\mathrm{N} / \mathrm{A}$ & N/A & $\mathrm{N} / \mathrm{A}$ & $\mathrm{N} / \mathrm{A}$ \\
\hline Rest pain at 48 hours $(\mathrm{cm})$ & 2 & $2.88(1.51)$ & $3.94(1.33)$ & $-1.40(-2.97$ to 0.17$)$ & $0.08\left(P_{c}=0.012\right)$ & $<0.00001$ & $95 \%$ & $\oplus \oplus \ominus \ominus$ \\
\hline $\begin{array}{l}\text { Oral morphine } \\
\text { consumption at } 2 \text { hours } \\
\text { (PACU) (mg) }\end{array}$ & 4 & $2.82(2.76)$ & $4.51(4.13)$ & $-1.54(-3.53$ to 0.45$)$ & $0.13\left(P_{c}=0.025\right)$ & $<0.0001$ & $86 \%$ & $\oplus \oplus \oplus \ominus$ \\
\hline $\begin{array}{l}\text { Oral morphine } \\
\text { consumption at } 24 \text { to } 48 \\
\text { hours }(\mathrm{mg})^{*}\end{array}$ & $\mathrm{~N} / \mathrm{A}$ & $\mathrm{N} / \mathrm{A}$ & N/A & N/A & $\mathrm{N} / \mathrm{A}$ & N/A & $\mathrm{N} / \mathrm{A}$ & N/A \\
\hline $\begin{array}{l}\text { Time to analgesic request } \\
\text { (hours) }\end{array}$ & 2 & $23.80(35.23)$ & $2.76(5.44)$ & $21.19(-20.72$ to 63.10$)$ & $0.32\left(P_{c}=0.050\right)$ & $<0.00001$ & $96 \%$ & $\oplus \oplus \ominus \ominus$ \\
\hline Opioid related side effects & 11 & $44 / 314$ & $84 / 313$ & 0.43 (0.28 to 0.66$)$ & $0.0002\left(P_{c}=0.007\right)$ & 0.73 & $0 \%$ & $\oplus \oplus \oplus \oplus$ \\
\hline $\begin{array}{l}\text { Block-related } \\
\text { complications }\end{array}$ & 8 & $0 / 213$ & N/A & N/A & N/A & N/A & N/A & N/A \\
\hline Patient satisfaction & 3 & $6.75(1.27)$ & $5.10(1.29)$ & $1.15(-0.40$ to 2.71$)$ & $0.15\left(P_{c}=0.016\right)$ & $<0.00001$ & $96 \%$ & $\oplus \oplus \oplus \Theta$ \\
\hline Hospital discharge* & N/A & N/A & N/A & N/A & N/A & N/A & N/A & N/A \\
\hline $\begin{array}{l}\text { Persistent postsurgical } \\
\text { pain* }\end{array}$ & $\mathrm{N} / \mathrm{A}$ & $\mathrm{N} / \mathrm{A}$ & N/A & N/A & $\mathrm{N} / \mathrm{A}$ & N/A & $\mathrm{N} / \mathrm{A}$ & N/A \\
\hline Opioid dependence* & N/A & N/A & N/A & N/A & N/A & N/A & N/A & N/A \\
\hline $\begin{array}{l}\text { Health related quality } \\
\text { of life* }\end{array}$ & $\mathrm{N} / \mathrm{A}$ & $\mathrm{N} / \mathrm{A}$ & $\mathrm{N} / \mathrm{A}$ & N/A & $\mathrm{N} / \mathrm{A}$ & N/A & $\mathrm{N} / \mathrm{A}$ & $\mathrm{N} / \mathrm{A}$ \\
\hline
\end{tabular}

$\oplus \oplus \oplus \oplus$, high quality evidence; $\oplus \oplus \oplus \ominus$, moderate quality evidence; $\oplus \oplus \ominus \ominus$, low quality evidence, $\oplus \ominus \ominus \ominus$, very low-quality evidence.

* Outcome reported by less than three studies or was not measured.

cm, centimeter; ESPB, erector spinae plane block; GRADE, Grades of Recommendation, Assessment, Development, and Evaluation; mg, milligrams; N/A, not applicable; PACU, post-anesthesia care unit; ; $\mathrm{P}$, corrected threshold of statistical significance.

\section{Primary and secondary outcomes}

The two co-primary outcomes of this meta-analysis were the postoperative 24 hours (1) cumulative postoperative oral morphine equivalent consumption (mg) and (2) difference in the area under the curve (AUC) of the weighted pooled rest pain severity scores. For the AUC analysis, the weighted pool rest pain scores at 1 hour (post-anesthesia care unit, PACU), 6 hours, 12 hours, and 24 hours postoperatively were used at time points that permit the analgesic effectiveness and capture ESPB onset and offset.

Secondary outcomes included cumulative postoperative oral morphine consumption (mg) during PACU stay as well as the 24-hour to 48-hour time interval; time-to-first analgesic request (hours); time to hospital discharge (hours); postoperative pain severity scores (visual analog scale, VAS) at individual time points (1 hour, 6 hours, 12 hours, 24 hours, 36 hours, and 48 hours postoperatively); patient satisfaction (VAS); postoperative opioid related side effects (postoperative nausea and vomiting, excessive sedation, respiratory depression, pruritus, urinary retention, or constipation); block-related complications (pneumothorax, nerve injury, or local anesthetic systemic toxicity); and long-term (incidence of persistent postsurgical pain, healthrelated quality of life, opioid dependence, and pain-related disability).

\section{Measurement of outcome data}

For the purposes of this review, all postoperative pain scores were converted to equivalent 0 to $10 \mathrm{~cm}$ VAS scores. ${ }^{18}$ All postoperative opioid analgesics administered were converted to oral morphine equivalents $(\mathrm{mg}) ;^{19}$ and all measures of patient satisfaction were converted to a VAS scores $(0=$ least satisfied and $10=$ most satisfied). ${ }^{18}$ Time-to-event data were presented in hours.

\section{Statistical analyses}

We extracted the mean and SD for continuous outcomes; in situations where other measures of centrality and dispersion were reported, previously described statistical conversions were used to estimate these values. ${ }^{20-23}$ For dichotomous outcomes, data were converted to overall incidence numbers. In cases where distinct pain scores were presented were for the breast and axilla, a weighted mean for pain in these two areas was calculated. Data available from one study were presented qualitatively.

\section{Meta-analysis}

To account for potential heterogeneity among the pooled studies, continuous data were pooled using the inverse variance method with random-effects modeling, and dichotomous data was pooled using the Mantel-Haenszel with random-effects modeling. ${ }^{24}$ For the co-primary outcomes, AUC of pain score and 24-hour analgesic consumption, a weighted mean difference (WMD) with a 95\% CI and a mean difference with 95\% CI were calculated, respectively.

Similarly, for secondary outcomes, we calculated a WMD with 95\% CI for primary outcomes, and an OR with 95\% CI was calculated for dichotomous outcomes. A p value $<0.025$ was designated as the threshold of statistical significance for the two co-primary outcomes. For the secondary outcomes, we adjusted the threshold for statistical significance in each of the four comparison performed using the Bonferroni-Holm correction 
( $\mathrm{P}$, corrected threshold of statistical significance) to account for the several secondary outcomes analyzed. ${ }^{25}$

\section{Interpretation}

Both co-primary outcomes were interpreted in light of the minimal clinically importance difference. For 24-hour morphine consumption, the treatment effect was interpreted in light of a minimum clinically important difference of $30 \mathrm{mg}$ of oral morphine (or $10 \mathrm{mg}$ intravenous morphine). For 24-hour AUC of rest pain, we first pooled rest pain scores at each of the designated time points (PACU, and at 6, 12, and 24 hours) for each arm of the comparisons. The pooled scores were then used to estimate the AUC (expressed in centimeters (cm).hour (h)) and a mean difference of the AUC was calculated. This difference was interpreted in light of a clinically important difference ${ }^{2627}$ equivalent to $1.1 \mathrm{~cm}$ for acute pain assessment at a single time point, ${ }^{26}$ which extrapolates to $3.3 \mathrm{~cm} . \mathrm{h}$ for the full 24-hour interval, based on four measurements $(0,6,12$, and 24 hours) or three subintervals of 0 to 6 hours, 6 to 12 hours, and 12 to 24 hours.

\section{Trial sequential analysis}

To confirm adequacy of sample size and reliability of conclusions, we conduct a trial sequential analysis on the co-primary outcomes. A type I error of 5\%, a power of $80 \%$, and two-sided testing was used for this analysis. We calculated the required information size based on the calculated WMD for ESPB versus parenteral opioids for each primary outcome. This calculation incorporated a correction for heterogeneity based on the original pooled estimate. The O'Brien-Fleming $\alpha$-spending function was used to create boundaries for concluding superiority, inferiority, or futility. ${ }^{28} 29$

\section{Exploring heterogeneity}

For all outcomes in this review, an $\mathrm{I}^{2}$ statistic was calculated to evaluate heterogeneity, and values $>50 \%$ were considered indicative of significant heterogeneity in the pooled estimate. ${ }^{21}$ When this threshold was met for a primary outcome, metaregression analysis using mixed effects modeling was performed to explore the interaction between a priori specified clinical predictors and the treatment effect. A coefficient of determination $\left(\mathrm{R}^{2}\right)$ was also calculated to help quantify the degree to which a covariate explained the variation in treatment effect. Metaregression analysis was only performed if at least four studies were included in an estimate of effect, with at least two trials within a covariate subgroup. The predetermined covariates and potential sources of heterogeneity included: (i) invasiveness of surgery (partial mastectomy vs mastectomy vs mastectomy with sentinel node biopsy vs mastectomy with axillary dissection); (ii) block localization technique (ultrasound vs ultrasound and nerve stimulator vs anatomic); ${ }^{30}$ (iii) location of local anesthetic injection (superior to erector spinae muscle vs deep to the erector spinae muscle); (iv) type of local anesthetic used (short-acting (lidocaine and mepivacaine) vs intermediate/long-acting (bupivacaine, levobupivacaine, and ropivacaine) $;^{31}$ (v) dose of local anesthetic used (converted to mg of bupivacaine); (vi) volume of local anesthetic used (15 to $20 \mathrm{~mL}$ vs 20 to $30 \mathrm{~mL}$ vs 30 to 40 $\mathrm{mL}$ ); (vii) postoperative analgesic modality (multimodal, inclusive of opioid and other adjuvants vs opioid-only); 3233 and (viii) the addition of adjuvants that may prolong block duration (eg, epinephrine, dexamethasone, or dexmedetomidine). ${ }^{3435}$

In situations where meta-regression analysis could not be performed (ie, $<2$ trials available for a specific covariate), we resorted to sensitivity analysis with sequential exclusion.
Additional sensitivity analysis was pre-planned to examine the effect of excluding studies (1) published in non-indexed journals; (2) available as abstracts only; or (3) with high risk of bias in one or more domains of the Cochrane risk of bias tool.

\section{Assessment of publication bias}

The risk of publication bias in our primary outcomes was assessed using the Egger's regression test ${ }^{36}$ for all outcomes examined.

\section{Data management}

Meta-regression was performed using Comprehensive MetaAnalysis 3.0 (Engelwood, USA). Review Manager Software (RevMan V.5.2; Nordic Cochrane Centre, Cochrane Collaboration) was used to create forest and funnel plots.

\section{RESULTS}

Our literature search identified 64 unique citations; and additional hand searching of bibliography and abstracts from conference proceedings identified one ${ }^{37}$ potentially eligible citation. From resultant 65 citations, 42 were excluded based on title and abstract alone, due to irrelevant intervention $(n=2)$, irrelevant comparator $(n=3)$, incorrect patient population $(n=4)$, or for not being an RCT $(n=33)$. The remaining 23 potentially eligible citations had their full text reviewed. Of these, 14 were excluded because of irrelevant comparator $(n=12)^{8} 9111238-45$ and not being an RCT $(n=2),{ }^{4647}$ leaving nine trials. Additional screening of trial registries identified three ${ }^{48-50}$ eligible trials. Consequently, a total of $12 \mathrm{RCTs}^{4103748-56}$ were included in this systematic review and meta-analysis. The authors of four ${ }^{37} 48-50$ trials provided additional details that facilitated this review. One study had data extracted from graphs presented in the manuscript. ${ }^{53}$ A flow diagram of study inclusion is presented in online supplemental appendix B.

\section{Study characteristics}

The characteristics and outcomes of interest of the included studies presented in table 1 . All 12 randomized trials ${ }^{4} 103748-56$ included adult females undergoing breast cancer surgery with or without axillary interventions under general anesthesia. These trials included 699 patients, of which 348 of which received ESPB and 351 received parenteral opioids alone (Control). All 12 studies ${ }^{4103748-56}$ reported pain scores, and 10 studies ${ }^{4103749-5456}$ reported postoperative analgesic consumption, the designated co-primary outcomes.

The ESPB technique and analgesic regimens used are presented in table 2. The time of administering ESPB was pre-induction of anesthesia in 11 studies ${ }^{4} 103749-56$ and post-induction in one study. ${ }^{48}$ All $12^{4} 103748-56$ studies used ultrasound localization to deposit local anesthetic below erector spinae muscle in 11 trials ${ }^{4} 10^{48-56}$ and one $e^{37}$ did not specify the location. All blocks ${ }^{4} 1037$ 48-56 were performed between the T2 to T5 levels using bupivacaine $(0.25 \%$ to $0.5 \%)$ in six studies 4851525456 and ropivacaine $(0.2 \%$ to $0.5 \%)$ in six studies. 103749505355 Nerve block adjuvants were not co-administered by any included study. The total volume of local anesthetic solution used for ESPB ranged from $16 \mathrm{~mL}$ to $40 \mathrm{~mL} .^{4103748-56}$ The risk of bias assessment for the included studies is presented in online supplemental appendix C.

\section{Primary outcomes}

Cumulative 24-hour oral morphine equivalent consumption

Data for this outcome were pooled from 649 patients (ESPB: 323 and Control: 326). ${ }^{4} 103748-5456$ Compared with parenteral 
opioids, ESPB reduced cumulative 24-hour oral morphine equivalent consumption by $-17.60 \mathrm{mg}(-24.27$ to -10.93$)$ $\left(\mathrm{p}<0.00001, \mathrm{I}^{2}=97 \%\right)$; but the magnitude of this difference remained short of the clinically important threshold $(30 \mathrm{mg}$ oral morphine) (figure 1). This result was characterized by high heterogeneity; meta-regression analysis was performed to explore the sources of heterogeneity did not detect an association between morphine consumption and (1) invasiveness of surgery $\left(\mathrm{R}^{2}=0.15, \mathrm{p}=0.26\right)$; (2) local anesthetic dose $\left(\mathrm{R}^{2}=0, \mathrm{p}=0.90\right)$; (3) local anesthetic volume $\left(\mathrm{R}^{2}=0, \mathrm{p}=0.80\right)$; and (4) postoperative analgesic modality $\left(\mathrm{R}^{2}=0, \mathrm{p}=0.55\right)$. Meta-regression could not be performed for the remaining covariates because all studies ${ }^{4} 103748-5456$ used ultrasound localization to inject longacting local anesthetics solution devoid of adjuvants. Our results were robust to sensitivity analysis for location of local anesthetic deposition. ${ }^{37}$ The treatment effect was also robust to sensitivity analysis when trials that were published as abstracts, ${ }^{37}$ identified from trial registries, ${ }^{374-50}$ or had a high risk of bias in one or more Cochrane domains ${ }^{10} 37484951525456$ were excluded from analysis. The risk of publication bias was low for this comparison $(\mathrm{p}=0.27)$, and quality of evidence was downgraded to moderate due to heterogeneity.

Trial sequential analysis for cumulative 24-hour oral morphine equivalent consumption (based on a WMD of $17.60 \mathrm{mg}$ between ESPB and parenteral opioids) revealed adequacy of sample size. The cumulative z-curve surpassed the boundary of superiority of ESPB over parenteral opioids for reducing 24-hour oral morphine equivalent consumption, and also surpassed the optimal information size of 198 patients (online supplemental appendix D).

\section{Difference in the AUC of rest pain}

Data for this outcome were pooled from 589 patients (ESPB: 293 and Control 296) at each of the PACU, ${ }^{4} \quad 10 \quad 37 \quad 48-51 \quad 53-56 \quad 6$-hour ${ }^{4} 10 \quad 37$ 48-51 $53-56$ and 24-hour ${ }^{4} 1037$ 48-51 53-56 time points, and 495 patients (ESPB: 246 and Control: 249) at the 12-hour ${ }^{4} 103748505154-56$ time point. Compared with parenteral opioids, ESPB decreased the AUC of the pooled rest pain scores by $-2.74 \mathrm{~cm} . \mathrm{h}(-3.09$ to $-2.39)(p<0.00001)$ over the 24-hour interval; however; but the magnitude of this difference remained short of the clinically important threshold $(3.3 \mathrm{~cm} . \mathrm{h})$ (figure 2$)$. The quality of evidence was downgraded to moderate due to heterogeneity in the pooled estimates for the individual time points.

Trial sequential analysis for cumulative difference for AUC rest pain over 24-hour (based on a mean difference of $0.90 \mathrm{~cm}$ between ESPB and parenteral opioids) also revealed adequacy of sample size. The cumulative z-curve surpassed the boundary of superiority of ESPB over parenteral opioids for reducing AUC rest pain severity, and also surpassed the optimal information size of 1593 patients (online supplemental file 4).

\section{Analgesic outcomes}

Rest pain at individual time points

ESPB improved pain control in the PACU, 41037 48-51 53-56 and at 6-hour, ${ }^{4} 1521455154-57$ 12-hour, ${ }^{4} 103748505154-56$ and 24-hour ${ }^{4} 103748-5153-56$ time points by mean differences of -1.17 $\mathrm{cm}(-1.68$ to -0.66$)\left(\mathrm{p}<0.00001, \mathrm{I}^{2}=83 \%\right),-1.17 \mathrm{~cm}(-1.67$ to -0.66$)\left(\mathrm{p}<0.00001, \mathrm{I}^{2}=82 \%\right),-0.85 \mathrm{~cm}(-1.53$ to -0.16$)$ $\left(\mathrm{p}=0.02, \mathrm{I}^{2}=89 \%\right)$, and $-0.72 \mathrm{~cm}(-1.15$ to -0.28$)(\mathrm{p}=0.001$, $\mathrm{I}^{2}=87 \%$ ), respectively (figure 3 , table 3 ). The difference in PACU and 6 hours surpassed the clinically important threshold (1.1 $\mathrm{cm}$ ); but this was not the case for 12 hours and 24 hours, and no further benefits were observed beyond 24 hours. ${ }^{1055}$ Furthermore, the difference observed at 12 hours was rendered nonsignificant when the Bonferroni-Holm correction was applied $\left(\mathrm{p}>\mathrm{P}_{\mathrm{c}}=0.01\right)$. Evidence quality was downgraded to moderate at PACU, 6, 12, and 24 hours due to heterogeneity, and low at 48 hours due to heterogeneity and imprecision.

\section{Analgesic consumption in PACU (2 hours)}

Four studies ${ }^{405156}$ evaluated analgesic consumption in PACU. Compared with parenteral opioids, adding ESPB did not improve opioid consumption in the PACU (table 3). Evidence quality of was downgraded to moderate due to heterogeneity.

\section{Cumulative 24 to 48 hours morphine consumption}

None of the studies reviewed evaluated this outcome.

\section{Time-to-first analgesic request}

Two studies ${ }^{50} 55$ evaluated time-to-first analgesic request. Compared with parenteral opioids, adding ESPB did not prolong time-to-first analgesic request. (table 3). Evidence quality was downgraded to low due to heterogeneity and imprecision.

\section{Patient satisfaction}

Three studies ${ }^{48} 4954$ evaluated patient satisfaction. Compared with parenteral opioids, ESPB did not improve patient satisfaction (table 3). Evidence quality was downgraded to moderate due to heterogeneity.

\section{Time-to-hospital discharge}

None of the studies reviewed evaluated this outcome.

Opioid-related side effects

Eleven studies ${ }^{4} 103749-56$ reported opioid-related side effects. Compared with parenteral opioids, ESPB reduced the OR $(95 \%$ $\mathrm{CI})$ of developing nausea and vomiting by 0.43 (0.28 to 0.66$)$ $\left(\mathrm{p}=0.0002, \mathrm{I}^{2}=0 \%\right)($ table 3$)$. Evidence quality was high for this outcome.

\section{Block-related complications}

Eight studies ${ }^{37} 49-55$ evaluated block-related complications. None of the patients in this comparison experienced any complications (table 3).

\section{Long-term outcomes}

None of the studies reviewed evaluated health-related quality of life, persistent postsurgical pain and opioid dependence.

\section{DISCUSSION}

Our systematic review and meta-analysis provides novel evidence defining the clinical role of ESPB in pain control following breast cancer surgery. Adding ESPB to parenteral analgesia was found to offer modest short-term benefits, including improvements in 24-hour AUC pain severity and cumulative opioid consumption. When put into clinical context, the statistically significant benefits observed lose their importance. For example, the opioid-sparing effect (reduction of $17.60 \mathrm{mg}$ of oral morphine) is equivalent to $0.73 \mathrm{mg}$ of oral morphine per hour or a total of two $5 \mathrm{mg}$ tablets of oxycodone over 24 hours. The modest benefits have to also be balanced against potential risks and complications of ESPB, which include pneumothorax ${ }^{58}$ local anesthetic toxicity, ${ }^{59}$ and nerve injury. ${ }^{60}$ 
It is notable that despite similarities with some of the results of a recent review, ${ }^{7}$ our conclusions regarding the clinical role of ESPB are starkly different. This difference is first due to our interpretation of statistically significant findings in the context of clinically important differences. As such, the modest improvements in pain scores (0.72 to $1.17 \mathrm{~cm}$ on a VAS scale) observed with ESPB block at the time points assessed fell short of the preset clinical threshold for the 24-hour period, and even short of thresholds of smaller magnitudes that have been reported in pain literature (eg, based on an minimal clinically important difference of $1.3 \mathrm{~cm}){ }^{61}{ }^{62}$ The different interpretation can also be attributed to focusing our estimate of ESPB treatment effect on evidence from comparisons with parenteral analgesia, instead of multiple comparisons with active comparators (ie, other truncal blocks), which are best left to a network meta-analysis. Unless ethically compelled, evaluating the efficacy of new interventions should be conducted via comparisons to placebo to improve accuracy and reduce biases. ${ }^{13}$ This particularly applies to studies of new nerve blocks, where there are no such ethical concerns, as long as alternative analgesic strategies (eg, parenteral analgesia) are made available to study participants.

The expanding list of fascial plane truncal blocks ${ }^{57}$ 63-65 promoted for breast and thoracic surgery has largely stemmed from a need for a simpler and safer paravertebral block (PVB) alternative. ${ }^{66-69}$ ESPB in specific may partially address these challenges, owing to the simplicity of its landmarks, decreased proximity to vital structures, and even potential utility in the anti-coagulated patients. ${ }^{70}$ However, the analgesic profile of ESPB does not seems to bear up for comparisons with parenteral analgesia. Furthermore, the potential safety advantage cannot be confirmed until larger studies are available. In contrast, the pectoralis myofascial plane (PECS) block, among the various PVB alternatives, is now supported by consistent level I evidence. ${ }^{72-74}$ Not surprisingly, PECS block possesses important prerequisites, including extensive $\mathrm{T} 2$ to $\mathrm{T} 5$ dermatomal spread, ${ }^{75}$ and blockade of the long thoracic, thoracodorsal, and medial and lateral pectoral nerves, thereby enabling it to provide effective analgesia to the entire breast and axilla. ${ }^{77}$

It is curious that the magnitude of analgesic benefits observed with ESPB were modest. One plausible explanation relates to the block's mechanism of action. By deposition of local anesthetic deep to the erector spinae muscle at the level of T5, ESPB has been presented as an intervention capable of blocking thoracic spinal nerves between T1 and L3 levels. ${ }^{12}$ However, several controversies mark the proposed ESPB mechanisms of action and extent of anatomical spread. Cadaveric studies examining ESPB have been conflicting, with several suggesting very limited spread to the paravertebral space and sympathetic thoracic chain, ${ }^{78-80}$ while few have reported some degree of penetration. ${ }^{81}{ }^{82}$ Similarly, recent in vivo MRI studies have also suggested that cephalocaudal spread to the paravertebral space and sympathetic chain is highly variable. ${ }^{79}$ These contrasting results signal that inconsistency of spread and variability of dermatomal coverage may be an intrinsic characteristic of ESPB, owing to the nature of the fascial planes between the spinalis, longissimus thoracis, and iliocostalis muscles that comprise the erector spinae muscles. As with other fascial blocks, spread is expectedly volume dependent; ${ }^{83}$ but even when accounting for that, spread remains inconsistent, blockade of the dorsal rami seems to be the only common denominator. ${ }^{84}$ Such inconsistency and variability are in a tradeoff with efficacy and reliability; and may explain why case reports and small case series ${ }^{58}$ have been successful in reporting ESPB benefits, while clinical trials were not. ${ }^{85}$ Indeed, a recent investigation of the role of ESPB for rib fractures notably found no benefit when compared sham block. ${ }^{85}$
There are several strengths of our meta-analysis. The comprehensive literature search included non-English trials as well as additional data provided by authors of relevant trials. The pooled sample size allowed drawing statistical inferences, and the results were interpreted in the context of clinically important differences, allowing a meaningful estimate of the efficacy of ESPB. The majority of patients in this review had modified radical mastectomy, a procedure known for its significant postoperative pain levels; ${ }^{86}$ and the use of an AUC analysis allowed accounting for time-based variations in analgesic efficacy in this population. Finally, the adjusted threshold of statistical significance served to increase accuracy and reduce the risk of type I error.

Our review also has notable limitations. Being a review of several smaller trials ( $<50$ patients per study), there is always a concern when attempting to produce an accurate estimate of the treatment effect. In addition, lack of data prevented examining several important outcomes, including health-related quality of life, persistent postsurgical pain, pain-related disability, and opioid dependence. Despite the success in resolving some of the heterogeneity by meta-regression and sensitivity analysis, some residual heterogeneity remained unexplained by the prespecified covariates. Finally, though ESPB complications were not detected in this review, the sample size included remains too small to examine this rare outcome.

\section{CONCLUSIONS}

Our systematic review and meta-analysis of ESPB 24-hour postoperative pain control and opioid-sparing effects following breast cancer surgery yielded moderate quality evidence of statistically significant but clinically unimportant benefits when the block is added to parenteral analgesia. Current evidence does not support routine use of ESPB. Given the very modest shortterm benefits and the risk complications, the block should be considered on a case-by-case basis.

Correction notice This article has been corrected since it published Online First. Negative signs have been added to values throughout the article and reference 26 has been corrected.

Twitter Nasir Hussain @nasir418, Colin JL McCartney @colinjmccartney and Faraj W Abdallah @Faraj_RegAnesth

Contributors All authors contributed meaningfully to the manuscript.

Funding The authors have not declared a specific grant for this research from any funding agency in the public, commercial or not-for-profit sectors.

Competing interests None declared.

Patient consent for publication Not required.

Provenance and peer review Not commissioned; externally peer reviewed.

Data availability statement Data are available upon reasonable request. All data relevant to the study are included in the article or uploaded as supplementary information.

\section{ORCID iDs}

Nasir Hussain http://orcid.org/0000-0003-0353-1002

Richard Brull http://orcid.org/0000-0002-7708-8843

Faraj W Abdallah http://orcid.org/0000-0003-2435-6186

\section{REFERENCES}

1 Forero M, Adhikary SD, Lopez H, et al. The erector spinae plane block: a nove analgesic technique in thoracic neuropathic pain. Reg Anesth Pain Med 2016:41:621-7.

2 Adhikary SD, Pruett A, Forero M, et al. Erector spinae plane block as an alternative to epidural analgesia for post-operative analgesia following video-assisted thoracoscopic surgery: a case study and a literature review on the spread of local anaesthetic in the erector spinae plane. Indian J Anaesth 2018:62:75-8.

3 Kot $\mathrm{P}$, Rodriguez $\mathrm{P}$, Granell $\mathrm{M}$, et al. The erector spinae plane block: a narrative review. Korean J Anesthesiol 2019;72:209-20. 
4 Gürkan Y, Aksu C, Kuş A, et al. Erector spinae plane block and thoracic paravertebral block for breast surgery compared to IV-morphine: a randomized controlled trial. J Clin Anesth 2020;59:84-8.

5 ElHawary $\mathrm{H}$, Abdelhamid K, Meng F, et al. Erector spinae plane block decreases pain and opioid consumption in breast surgery: systematic review. Plast Reconstr Surg Glob Open 2019;7:e2525.

6 Huang W, Wang W, Xie W, et al. Erector spinae plane block for postoperative analgesia in breast and thoracic surgery: a systematic review and meta-analysis. J Clin Anesth 2020;66:109900.

7 Leong RW, Tan ESJ, Wong SN, et al. Efficacy of erector spinae plane block for analgesia in breast surgery: a systematic review and meta-analysis. Anaesthesia 2020. doi:10.1111/anae.15164. [Epub ahead of print: 01 Jul 2020].

8 Eldemrdash AM, Abdelzaam E-SM. By ultrasonic-guided erector spinae block, thoracic paravertebral block versus serratus anterior plane block by articaine with adrenaline during breast surgery with general anesthesia: a comparative study of analgesic effect post-operatively: double blind randomized, controlled trial. Open J Anesthesiol 2019;09:68-82.

9 Moustafa MA, Alabd AS, Ahmed AMM, et al. Erector spinae versus paravertebral plane blocks in modified radical mastectomy: randomised comparative study of the technique success rate among novice anaesthesiologists. Indian J Anaesth 2020;64:49-54.

10 Wang HJ, Liu Y, Ge WW, et al. [Comparison of ultrasound-guided serratus anterior plane block and erector spinae plane blockperioperatively in radical mastectomy]. Zhonghua Yi Xue Za Zhi 2019;99:1809-13.

11 Sinha C, Kumar A, Kumar A, Prasad C, et al. Pectoral nerve versus erector spinae block for breast surgeries: a randomised controlled trial. Indian J Anaesth 2019;63:617-22.

12 Swisher MW, Wallace AM, Sztain JF, et al. Erector spinae plane versus paravertebral nerve blocks for postoperative analgesia after breast surgery: a randomized clinica trial. Reg Anesth Pain Med 2020;45:260-6.

13 Guideline ICHHT. Choice of control group and related issues in clinical trials e10. Choice E, 2000.

14 Moher D, Liberati A, Tetzlaff J, et al. Preferred reporting items for systematic reviews and meta-analyses: the PRISMA statement. J Clin Epidemiol 2009;62:1006-12.

15 Higgins JPT, Altman DG, Gotzsche PC, et al. The Cochrane Collaboration's tool for assessing risk of bias in randomised trials. BMJ 2011;343:d5928.

16 Guyatt GH, Oxman AD, Kunz R, et al. Going from evidence to recommendations. BMJ 2008;336:1049.

17 Guyatt G, Oxman AD, Akl EA, et al. Grade guidelines: 1. IntroductionGRADE evidence profiles and summary of findings tables. J Clin Epidemiol 2011;64:383-94.

18 Thorlund K, Walter SD, Johnston BC, et al. Pooling health-related quality of life outcomes in meta-analysis-a tutorial and review of methods for enhancing interpretability. Res Synth Methods 2011;2:188-203.

19 Association CP. Compendium of pharmaceuticals and specialties: the Canadian drug reference for health professionals. 45 edn. Ottawa, Ontario, Canada: Canadian Pharmacists Assoc, 2010.

20 Wan X, Wang W, Liu J, et al. Estimating the sample mean and standard deviation from the sample size, median, range and/or interquartile range. BMC Med Res Methodol 2014; $14: 135$

21 The Cochrane Collaboration. Cochrane handbook for systematic reviews of interventions version 5.1.0, 2011.

22 Furukawa TA, Barbui C, Cipriani A, et al. Imputing missing standard deviations in meta-analyses can provide accurate results. J Clin Epidemiol 2006;59:7-10.

23 Moore A, McQuay H, Gavaghan D. Deriving dichotomous outcome measures from continuous data in randomised controlled trials of analgesics. Pain 1996;66:229-37.

24 DerSimonian R, Laird N. Meta-analysis in clinical trials. Control Clin Trials 1986;7:177-88.

25 Holm S. A simple sequentially rejective multiple test procedure. Scand Stat Theory App/ 1979;6:65-70.

26 Kelly AM. The minimum clinically significant difference in visual analogue scale pain score does not differ with severity of pain. Emerg Med J 2001;18:205-7.

27 Cook CE. Clinimetrics corner: the minimal clinically important change score (mcid): a necessary pretense. J Man Manip Ther 2008;16:E82-3.

28 O'Brien PC, Fleming TR. A multiple testing procedure for clinical trials. Biometrics 1979;35:549-56.

29 Thorlund KEet al. User manual for trial sequential analysis (TSA). , 2011: 1, 1-115.

30 Ueshima H, Hiroshi O. Ultrasound and nerve stimulator guidance decreases the use of local anesthetic for 1st injection in pectoral nerve blocks. J Clin Anesth 2018;48:21.

31 Moore DC, Bridenbaugh LD, Bridenbaugh PO, et al. Bupivacaine for peripheral nerve block: a comparison with mepivacaine, lidocaine, and tetracaine. Anesthesiology 1970;32:460-3.

32 Elia N, Lysakowski C, Tramèr MR. Does multimodal analgesia with acetaminophen, nonsteroidal antiinflammatory drugs, or selective cyclooxygenase-2 inhibitors and patient-controlled analgesia morphine offer advantages over morphine alone? metaanalyses of randomized trials. Anesthesiology 2005;103:1296-304.

33 Cho C-H, Song K-S, Min B-W, et al. Multimodal approach to postoperative pain control in patients undergoing rotator cuff repair. Knee Surg Sports Traumatol Arthrosc 2011;19:1744-8.
34 Hassan HG, Renck H, Lindberg B, et al. Effects of adjuvants to local anaesthetics on their duration. II. studies of some substituted dextrans and other macromolecules in rat infraorbital nerve block. Acta Anaesthesio/ Scand 1985;29:380-3.

35 Patil KN, Singh ND. Clonidine as an adjuvant to ropivacaine-induced supraclavicular brachial plexus block for upper limb surgeries. J Anaesthesiol Clin Pharmacol 2015;31:365-9.

36 Egger M, Davey Smith G, Schneider M, et al. Bias in meta-analysis detected by a simple, graphical test. BMJ 1997;315:629-34.

37 Arora S, Sharma S, Jafra A, et al. Esra19-0136 efficacy of erector spinae plane block for postoperative analgesia in breast cancer surgery: a randomized controlled trial. Reg Anesth Pain Med 2019;44:A199.

38 Ueshima H, Otake H. A combination of an erector spinae plane block and a transversus thoracic muscle plane block for partial mastectomy. J Clin Anesth 2019;54:1.

39 Oksuz G, Bilgen F, Arslan M, et al. Ultrasound-guided bilateral erector spinae block versus tumescent anesthesia for postoperative analgesia in patients undergoing reduction mammoplasty: a randomized controlled study. Aesthetic Plast Surg 2019:43:291-6.

40 Altıparmak B, Korkmaz Toker M, Uysal Ali Ihsan, Uysal A, et al. Comparison of the efficacy of erector spinae plane block performed with different concentrations of bupivacaine on postoperative analgesia after mastectomy surgery: ramdomized, prospective, double blinded trial. BMC Anesthesiol 2019;19:31.

41 Altıparmak B, Korkmaz Toker M, Uysal Ali Ihsan, Uysal A, et al. Comparison of the effects of modified pectoral nerve block and erector spinae plane block on postoperative opioid consumption and pain scores of patients after radical mastectomy surgery: a prospective, randomized, controlled trial. J Clin Anesth 2019;54:61-5

42 El Ghamry MR, Amer AF. Role of erector spinae plane block versus paravertebral block in pain control after modified radical mastectomy. A prospective randomised trial. Indian J Anaesth 2019;63:1008-14.

43 Gad M, Abdelwahab K, Abdallah A, et al. Ultrasound-guided erector spinae plane block compared to modified pectoral plane block for modified radical mastectomy operations. Anesth Essays Res 2019;13:334-9

44 Shukla S, Bhandari R, Banarjee S, et al. Comparison of usg guided pecs block (i \& ii) and erector spinae block for postoperative analgesia in breast surgeries using $0.2 \%$ ropivacaine. J Appl Dent Med Sci 2019;18:6-10.

45 IRCT. Comparison the effect of erector spinae block vs pectoral 1 block on post operative pain, nausea, and vomiting in breast mass surgeries: a double blind randomized study. IRCT: $0181126041760 N 1$. Available: http://en.irct.ir

46 Malawat A, Verma K, Jethava D, et al. Erector spinae plane block for complete surgica anaesthesia and postoperative analgesia for breast surgeries: a prospective feasibility study of 30 cases. Indian J Anaesth 2020;64:118-24.

47 Hong B, Bang S, Chung W, et al. Multimodal analgesia with multiple intermittent doses of erector spinae plane block through a catheter after total mastectomy: a retrospective observational study. Korean J Pain 2019;32:206-14.

48 Divatia JV, Thiagarajan P. Check the usefulness of local anesthetic injection into the erector spinae muscle (erector spinae block) in patients operated for breast cancer. CTRI: 019701, 2020. Available: http://www.ctri.nic.in

49 Gupta N, Sarma R. To compare the efficacy of opioid free general anesthesia with opioid based general anesthesia on post operative morphine consumption in patients undergoing breast cancer surgery: a prospective randomized control study. CTRI: 020865, 2020. Available: http://www.ctri.nic.in

50 Marzouk SB. Postoperative analgesia in breast cancer surgery: safety and efficiency of ultrasound guided erector spinae plane block. ClinicalTrials.gov: NCT03769428, 2020 Available: www.clinicaltrials.gov

51 Aksu C, Kuş A, Yörükoğlu HU, et al. Analgesic effect of the bi-level injection erector spinae plane block after breast surgery: a randomized controlled trial. Agri 2019;31:132-7.

52 Seelam S, Nair AS, Christopher A, et al. Efficacy of single-shot ultrasound-guided erector spinae plane block for postoperative analgesia after mastectomy: a randomized controlled study. Saudi J Anaesth 2020;14:22-7.

53 Yao Y, Li H, He Q, et al. Efficacy of ultrasound-guided erector spinae plane block on postoperative quality of recovery and analgesia after modified radical mastectomy: randomized controlled trial. Reg Anesth Pain Med 2020;45:5-9.

54 Singh S, Kumar G. Ultrasound-Guided erector spinae plane block for postoperative analgesia in modified radical mastectomy: a randomised control study. Indian J Anaesth 2019;63:200-4.

$55 \mathrm{He} \mathrm{W}$, Wu Z, Zu L, et al. Application of erector spinae plane block guided by ultrasound for postoperative analgesia in breast cancer surgery: a randomized controlled trial. Cancer Commun 2020;40:122-5.

56 Gürkan Y, Aksu C, Kuş A, et al. Ultrasound guided erector spinae plane block reduces postoperative opioid consumption following breast surgery: a randomized controlled study. J Clin Anesth 2018;50:65-8.

57 Murouchi T, Yamakage M. Retrolaminar block: analgesic efficacy and safety evaluation. J Anesth 2016;30:1003-7

58 Tsui BCH, Fonseca A, Munshey F, et al. The erector spinae plane (ESP) block: a pooled review of 242 cases. J Clin Anesth 2019;53:29-34. 
59 Tulgar S, Selvi O, Senturk O, et al. Ultrasound-guided erector spinae plane block: indications, complications, and effects on acute and chronic pain based on a singlecenter experience. Cureus 2019;11:e3815.

60 De Cassai A, Bonvicini D, Correale C, et al. Erector spinae plane block: a systematic qualitative review. Minerva Anestesiol 2019;85:308-19.

61 Cepeda MS, Africano JM, Polo R, et al. What decline in pain intensity is meaningful to patients with acute pain? Pain 2003;105:151-7.

62 Todd KH, Funk KG, Funk JP, et al. Clinical significance of reported changes in pain severity. Ann Emerg Med 1996;27:485-9.

63 Onishi E, Murakami M, Nishino R, et al. Analgesic effect of double-level retrolaminar paravertebral block for breast cancer surgery in the early postoperative period: a placebo-controlled, randomized clinical trial. Tohoku J Exp Med 2018;245:179-85.

64 Roué C, Wallaert M, Kacha M, et al. Intercostal/paraspinal nerve block for thoracic surgery. Anaesthesia 2016;71:112-3.

65 Costache I, de Neumann L, Ramnanan CJ, et al. The mid-point transverse process to pleura (MTP) block: a new end-point for thoracic paravertebral block. Anaesthesia 2017;72:1230-6.

66 Terkawi AS, Tsang S, Sessler DI, et al. Improving analgesic efficacy and safety of thoracic paravertebral block for breast surgery: a mixed-effects meta-analysis. Pain Physician 2015;18:E757-80.

67 Richardson J, Lönnqvist PA, Naja Z. Bilateral thoracic paravertebral block: potential and practice. Br J Anaesth 2011;106:164-71.

68 Portela DA, Campoy L, Otero PE, et al. Ultrasound-guided thoracic paravertebral injection in dogs: a cadaveric study. Vet Anaesth Analg 2017:44:636-45.

69 Karmakar MK. Thoracic paravertebral block. Anesthesiology 2001;95:771-80.

70 Adhikary SD, Prasad A, Soleimani B, et al. Continuous erector spinae plane block as an effective analgesic option in anticoagulated patients after left ventricular assist device implantation: a case series. J Cardiothorac Vasc Anesth 2019;33:1063-7.

71 Chin KJ, Pawa A, Forero M, et al. Ultrasound-guided fascial plane blocks of the thorax: pectoral I and II, serratus anterior plane, and erector spinae plane blocks. Adv Anesth 2019;37:187-205.

72 Hussain N, Brull R, McCartney CJL, et al. Pectoralis-ii myofascial block and analgesia in breast cancer surgery: a systematic review and meta-analysis. Anesthesiology 2019;131:630-48.

73 Grape S, Jaunin E, El-Boghdadly K, et al. Analgesic efficacy of PecS and serratus plane blocks after breast surgery: a systematic review, meta-analysis and trial sequential analysis. J Clin Anesth 2020;63:109744.
74 Lovett-Carter D, Kendall MC, McCormick ZL, et al. Pectoral nerve blocks and postoperative pain outcomes after mastectomy: a meta-analysis of randomized controlled trials. Reg Anesth Pain Med 2019;44:923-8.

75 Blanco R, Fajardo M, Parras Maldonado T. Ultrasound description of PecS II (modified PecS I): a novel approach to breast surgery. Rev Esp Anestesiol Reanim 2012;59:470-5.

76 Naja Z, Lönnqvist PA. Somatic paravertebral nerve blockade. incidence of failed block and complications. Anaesthesia 2001;56:1184-8.

77 Kulhari S, Bharti N, Bala I, et al. Efficacy of pectoral nerve block versus thoracic paravertebral block for postoperative analgesia after radical mastectomy: a randomized controlled trial. Br J Anaesth 2016;117:382-6.

78 Govender S, Mohr D, Neels Van Schoor A, et al. The extent of cranio-caudal spread within the erector spinae fascial plane space using computed tomography scanning in a neonatal cadaver. Paediatr Anaesth 2020.

79 Schwartzmann A, Peng P, Maciel MA, et al. A magnetic resonance imaging study of local anesthetic spread in patients receiving an erector spinae plane block. Can J Anaesth 2020;67:942-8.

80 Ivanusic J, Konishi Y, Barrington MJ. A cadaveric study investigating the mechanism of action of erector spinae blockade. Reg Anesth Pain Med 2018;43:567-71.

81 Diwan S, Nair A. Is paravertebral-epidural spread the underlying mechanism of action of erector spinae plane block? Turk J Anaesthesiol Reanim 2020;48:86-7.

82 Bang S, Choi J, Kim ED. A high thoracic erector spinae plane block used for sympathetic block in patients with upper extremity complex regional pain syndrome. $J$ Clin Anesth 2020;60:99-100.

83 Onishi E, Toda N, Kameyama Y, et al. Comparison of clinical efficacy and anatomical investigation between retrolaminar block and erector spinae plane block. Biomed Res Int 2019;2019:1-8.

84 Aponte A, Sala-Blanch X, Prats-Galino A, et al. Anatomical evaluation of the extent of spread in the erector spinae plane block: a cadaveric study. Can J Anaesth 2019:66:886-93.

85 Barrett W, Tran B. The erector spinae plane block and its effects on respiratory status and pain management in rib fracture patients: a randomized controlled trial. San Francisco, California: American Society of Regional Anesthesia, 2020.

86 Tasmuth $\mathrm{T}$, von Smitten $\mathrm{K}$, Hietanen $\mathrm{P}$, et al. Pain and other symptoms after different treatment modalities of breast cancer. Ann Oncol 1995:6:453-9. 